ORIGINAL ARTICLE

\title{
Patterns of Surgically Treated Thyroid Disease: A Two Years Review at St. Paul Hospital Millennium medical Collage, Addis Ababa, Ethiopia
}

\author{
Yisihak Suga $^{1^{*}}$, Engida Abebe ${ }^{2}$
}

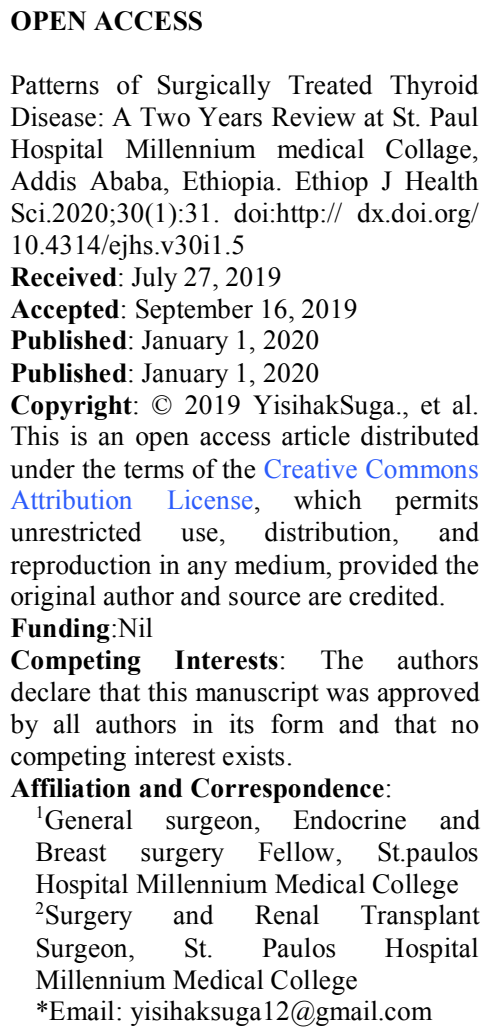

ABSTRACT

BACKGROUND: Thyroid disease is a common disorder of the endocrine system worldwide. It is a common problem in developing countries, including Ethiopia. The aim of this study was to determine the burden and the pattern of thyroid disease in St. Paul's Hospital Millennium Medical College, Addis Ababa, Ethiopia.

METHODS: A retrospective review of patients' medical records over a two-year period, January 2013-december 2014, was done. OR log books, and individual patient medical records was used for the review. Data was analyzed with SPSS version 20.

RESULTS: A total of 2201 general surgical operations were done in a two-year period. Of these, $250(11 \%)$ were for thyroid surgery. Records of 222(88.8\%) patients were found and used for analysis. Females accounted for $91.4 \%$ with $F: M$ ratio of 10.7:1. The common mode of presentations were anterior neck swelling (91.4\%) and toxic (29.7\%) and pressure symptoms(19.4\%). The common physical findings identified were multi nodular goiter (57.2\%), diffuse goiter (23.9\%) and solitary nodule (5.8\%). FNAC showed that Nodular colloid goiter was common diagnosis (68.5\%). Neoplasms accounted for $15.9 \%$ of the diagnosis; of this follicular neoplasm make (54\%) and papillary cancer (20\%). Functionally, hyperthyroid goiter $28.8 \%$ and euthyroid goiters (64\%). Transient hypocalcaemia (3.2\%) and hoarseness of voice (1.8\%) were the commonest complications. There was no postoperative mortality. CONCLUSION: Hyperthyroidism and neoplasms make significant proportions of the patients. Follicular neoplasm is the commonest tumor. Morbidity and mortality rates are comparable to the literature.

KEYWORDS: Goiter, thyroid, thyroidectomy 


\section{INTRODUCTION}

Thyroid enlargement or goiter is a common disorder of the endocrine system worldwide. The thyroid gland is affected in many physiologic and pathologic conditions. These conditions are either because of functional disorder or enlargement of the gland for different pathological reasons $(1,3)$. Benign thyroid conditions, which are still the commonest, are the result of iodine deficiency. Although surgically treated thyroid swellings vary widely from one geographical area to another, thyroid disorders are common in Africa. The prevalence areas of thyroid swellings mainly from iodine deficiency are common highlands. Currently, most African countries, including Ethiopia, are implementing universal salt iodization programs to tackle the condition.

Thyroid pathologies, whether benign or malignant, give patients a variety of morbidities and can also cause deaths. Reasons for thyroid surgery include cosmetic, pressure symptoms, malignant change, etc. Thyroid surgery constitutes a significant proportion of major elective general surgery in the developing world. The attending complications are also considerable including hematoma collection, nerve injuries, hypocalcemia, etc.

There are limited studies on thyroid disease in Africa. The prevalence of thyroid disease was reported from few countries. For instance, the prevalence was $7.3 \%$ in Zambia, and $3.6 \%$ in Uganda. Although there is no population-based study regarding the prevalence of thyroid disease, it appears to be not uncommon in Ethiopia. Studies haves shown that goiters are very prevalent in Ethiopi; many hospitals are burdened with the disease. According to the UNICEF report in 1993, $78 \%$ of the total population of Ethiopia were exposed to iodine deficiency, $62 \%$ were iodine deficient and $26 \%$ had goiter. The rate of goiter was $59 \%$ (study done In Jimma, Southwest Ethiopia).

This study will be helpful to provide data about burden and pattern of thyroid diseases in our institution which indirectly reflect what happens in the community. It will also help to influence preventive measures and prepare necessary skilled professionals and materials.

\section{MATERIALS AND METHODS}

Retrospective review of charts was done to determine the burden and patterns of thyroid disease patients admitted to surgical wards in SPHMMC in the years 2013-2014. As the number of cases in two years of the study (2013-2014) was equal to the calculated sample size ( 246 at $\mathrm{P}=.2$, $\mathrm{E}=.05$ and $\mathrm{Z}=1.96$ ) all patients admitted to surgical wards and operated at the hospital in the given period were included in the study. Patients admitted with thyroid pathologies but discharged without operation were excluded from the study.

The list of the charts of patients was obtained from the logbook of the operation room and nursing documentations. Data were collected by trained medical interns and final year medical students by reviewing the charts of the patients using a pretested and validated data collection format. The data were entered into a computer and analyzed using SPSS 20 (Statistical Packages for Social Sciences).

Ethical clearance was obtained from institutional review board (IRB) of St. Paul's hospital millennium medical college. Confidentiality of patient's records was kept and no patient information was transferred to any other organ.

\section{RESULTS}

During the study period, a total of 2201 elective surgical operations were done. Of these, $250(11 \%)$ were for thyroid surgery. Records of $222(88.8 \%)$ patients were found and used for analysis. Out of these, females accounted for $91.4 \%$ of the cases with F:M ratio of 10.7:1. Most patients were in their $3^{\text {rd }}$ and $4^{\text {th }}$ decade of life and lived in urban area $(51.4 \%)$ (Table1). 
Table1:Socio demographic profile of patients operated for goiter in SPHMMC, January 2013-December 2014.

\begin{tabular}{llll}
\hline Description & & Frequency $(\mathbf{n}=\mathbf{2 2 2})$ & Percentage (100\%) \\
\hline Sex & Female & 203 & 91.4 \\
Age group & Male & 19 & 8.6 \\
& $<20$ & 23 & 10.4 \\
& $20-40$ & 137 & 61.7 \\
Residence & $41-60$ & 56 & 25.2 \\
& $>61$ & 6 & 2.7 \\
Religion & Urban & 114 & 51.4 \\
& Rural & 108 & 48.6 \\
& Orthodox & 140 & 63.1 \\
\multirow{2}{*}{ Marital status } & Muslim & 38 & 17.1 \\
& Protestant & 33 & 14.9 \\
& Others & 11 & 5.0 \\
& Single & 75 & 33.8 \\
& Married & 140 & 63.1 \\
& Widowed & 5 & 2.3 \\
\hline
\end{tabular}

The commonest reasons for seeking medical attention were anterior neck swelling (91.4\%), toxic symptoms $(4.1 \%)$ and pressure symptoms $(1.8 \%)$ (Table2). Common associated symptoms included toxic symptoms $(29.7 \%)$, pressure symptoms (19.4\%) and voice change (3.2\%).
For most patients $(57.7 \%)$, the duration of illness was less than five years. The remaining $(42.3 \%)$ presented after 5 years of developing goiter (Table2). The most common physical findings were multinodular goiter $(57.2 \%)$ and diffuse goiter $(23.9 \%)$. None of the patients had thyroid ultrasound (Table2).

Table2: Clinical finding of patients operated for goiter in SPHMMC, January 2013 - December 2014.

\begin{tabular}{|c|c|c|c|}
\hline & & No. & Percent \\
\hline \multirow{5}{*}{ Presenting Symptoms } & Anterior neck swelling & 203 & 91.4 \\
\hline & Toxic symptoms & 4 & 4.1 \\
\hline & Pressure symptoms & 9 & 1.8 \\
\hline & Weight loss & 1 & 1.4 \\
\hline & Change in voice & 3 & 0.5 \\
\hline \multirow[t]{2}{*}{ Associated symptoms } & None (other than the presenting symptoms) & 91 & 41 \\
\hline & Toxic symptoms & 66 & 29.7 \\
\hline \multirow{4}{*}{ Duration of presentation (years) } & $<5$ & 128 & 57.7 \\
\hline & $6-10$ & 61 & 27.5 \\
\hline & $11-20$ & 27 & 12.2 \\
\hline & $>20$ & 6 & 2.7 \\
\hline \multirow[t]{4}{*}{ PE finding } & MNG & 127 & 57.2 \\
\hline & Diffuse Goiter & 53 & 23.9 \\
\hline & Thyroid nodule & 35 & 15.8 \\
\hline & Cervical LAP & 3 & 1.4 \\
\hline
\end{tabular}

FNAC was done in 208 cases and showed Nodular colloid goiter for $(68.5 \%)$, Thyroid cysts $(4.5 \%)$, and Diffuse colloid goiter (4.1\%). Among the malignancies, Follicular neoplasm accounted for $(8.6 \%)$, papillary cancer $(3.2 \%)$, anaplastic cancer
$(2.7 \%)$ and medullary cancer $(0.9 \%)$ (Table 3$)$ and (Figure 1). Functionally, $68 \%$ of the patients were euthyroid goiter while $28.8 \%$ were hyperthyroid goiter and 1.9\% hypothyroid goiter (Table 3). Histologically, follicular neoplasms make (54\%) 
and papillary cancer $(20 \%)$ from the malignant conditions (Figure 1).

Table 3: Fine needle aspiration findings of patients operated at SPHMMC, January 2013 - December 2014.

\begin{tabular}{lll}
\hline FNAC finding & Frequency & Percent \\
\hline Nodullar colloid goiter & 152 & 68.5 \\
Follicular neoplasm & 19 & 8.6 \\
Thyroid cysts & 10 & 4.5 \\
Diffuse colloid & 9 & 4.1 \\
Papillary cancer & 7 & 3.2 \\
Anaplastic cancer & 6 & 2.7 \\
Medullary cancer & 2 & 0.9 \\
$\quad$ Adenomatous goiter & 2 & 0.9 \\
\multicolumn{1}{c}{ Thyroid cancer } & 1 & 0.5 \\
$\quad$ Not done & 14 & 6.3 \\
\hline
\end{tabular}

The most common types of surgeries done were had total thyroidedctomy(Figure 2). subtotal thyroidectomy (bilateral and unilateral added) (50\%), lobectomy and isthmesectomy $(24 \%)$, near total thyroidectomy $(14 \%)$ and Hypocalcaemia (3.2\%), hoarseness of voice $(1.8 \%)$ and surgical site infection (1.4\%)were the lobectomy alone $(7.8 \%)$. Only $4.2 \%$ the of patients commonest complications encountered (Table 4).

Table4:Post op complications encountered after thyroid surgeryat SPHMMC, January 2013 - December 2014

\begin{tabular}{lll}
\hline Complications & Frequency $(\mathbf{n = 2 2 2})$ & Percent $\mathbf{( 1 0 0 \% )}$ \\
\hline Hypocalcemia & 7 & 3.2 \\
Hoarseness of voice & 4 & 1.8 \\
Surgical site infection & 3 & 1.4 \\
Hospital acquired pneumonia & 2 & 0.9 \\
Bleeding & 1 & .5 \\
Hematoma & 1 & .5 \\
None & 204 & 91.9 \\
\hline
\end{tabular}

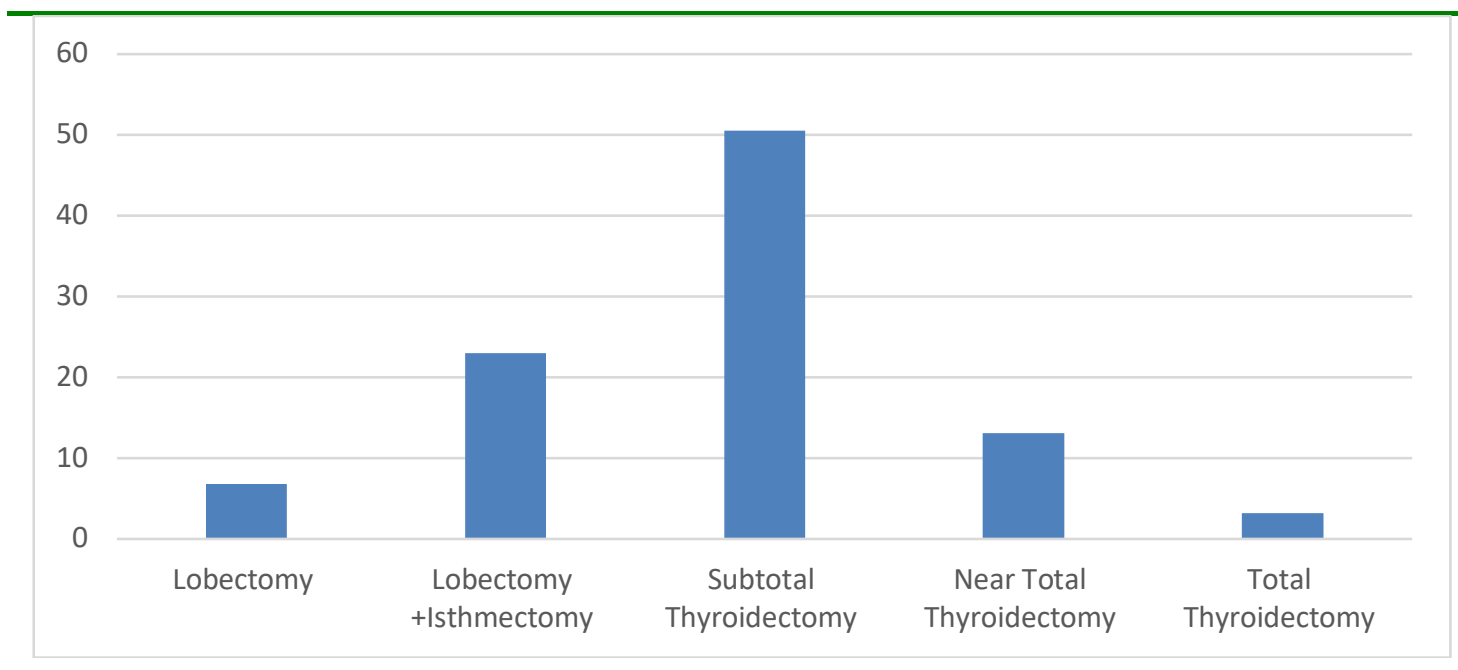

Figure 2: Types of surgeries done for thyroid disease at SPHMMC, January 2013-December 2014.

DOI: http://dx.doi.org/10.4314/ejhs.v30i1.5 


\section{DISCUSSION}

Diseases of the thyroid are of great importance especially in developing countries, where the disease is attributed to iodine deficiency $(5,7)$. According to $\mathrm{WHO}, 7 \%$ of the world population is suffering from clinically apparent goiter; the majority of them are from developing countries (7). During the study period, a total of 2201 general surgical operations were done in a two year period. Of these, $250(11 \%)$ were for thyroid surgery. Thyroid surgery constituted a significant proportion of major elective general surgery, which is a bit higher than other studies: Gondar, Ethiopia $(3.8 \%)(1)$ and Zambia (7.25\%)(2).

The increase may be attributed to the increased awareness of the society and early visit to health facilities. Thyroidectomy recently has become a routine procedure as result of safe anesthesia, antiseptics, fine surgical instruments and developments of new techniques, and is offering the chances of cure to many patients $(3,7)$.

Females predominate with a ratio of F:M (10.7:1). This is comparable to other studies: Gondar (5:2) (1) and Zambia (7.8:1)(2).For many women, thyroid problems first arise during times of hormonal unrest, such as childbearing and periods of prolonged or intense emotional, physical and mental stress, like pregnancy and menopause. The other reason for female predominance could be a result of autoimmune thyroid diseases (graves and hashimoto's thyroiditis) being common in females $(1,3,7,11)$.

Most of our patients were in their $3^{\text {rd }}$ and $4^{\text {th }}$ decades. The figure is comparable to other studies $(1,2)$. About $51.4 \%$ of the patients liveed in urban areas. The figure might not truly represent; instead, it tells us the increased awareness for early visit to health facilities and the availability of the service in nearby areas.

Most of the patients presented with a chief complaint of anterior neck swelling (91.4\%) followed by toxic symptoms (4.1\%). Although, $58 \%$ of the patients came to the hospital within five years of the illness, a significant number (42\%) present after five years. This late presentation is due to the smaller number of health facilities; even if there are, the far distance patients have to travel and also considering goiters as a normal thing, especially in rural areas $(1,5,12,13)$.

During physical examination, about $23.9 \%$ patients found to have diffuse goiters. None of these patients have been evaluated by ultrasonography. This could be the main reason for having less number of nodular goiters, as most diffuse goiters with physical examination will have nodules on thyroid sonography. Ultrasongraphy is one of the most popular radiological methods for diagnosing thyroid diseases since its first introduction in 1966-1967. It is more sensitive in detecting non-palpable thyroid nodules $(3,9,11)$.

In this study, nodular colloid goiter accounted for $68.5 \%$, being the most common pathologic presentation. According to the literature, benign thyroid diseases are more common than malignancies while colloid goiter is the common cause of thyroid disease in the world $(1,2,3,5,10)$.

The rate of thyroid malignancies $(15.9 \%)$ is found to be high as compared to other studies: Gondar $(10.2 \%)$ and Nigeria $(10.8 \%)(1,5)$. Follicular neoplasm is the commonest. The increased rate could be due to a multitude of factors. Possible explanations include; during the study period, the hospitals pathology unit was functioning well and the other possible reason is as the hospital is teaching center, difficult cases are handled frequently. The histological pattern is similar to other reports in Africa $(1,2,3,5,10)$. But, in most developed countries, papillary thyroid cancer predominates (11). This could be attributed to the fact that follicular neoplasms arise from long standing multinodular goiters in endemic $\operatorname{areas}(1,8,12,13)$.

Functionally, toxic goiter accounted for $28.8 \%$ which is higher compared to other studies: Gondar (3.6\%) and Zambia (3.6) (1,2).A similar increase was observed in Nigeria, Uganda and Iraq $(3,4)$. The increase could be due to increased use of iodized salt to combat endemic goiter and the increase in stressful life style. In our situation, the other reason is that, in most patients, thyroid function test was determined opposed to previous times where the study was done rarely as it was not available in most of governmental hospitals.

The most common type of surgery was subtotal thyroidectomy $(50 \%)$. However, the

DOI: http://dx.doi.org/10.4314/ejhs.v30i1.5 
current trend in most countries, especially in developed countries, is more to near total and total thyroidectomies (7). This, is mostly due to the increase in thyroid malignancies and the availability (with low cost) of L-thyroxin to threat hypothyroidism. These extensive surgeries are better in preventing recurrences in either toxic or malignancies $(7,11)$.

The rate of complications of thyroid surgery in our studywas in acceptable ranges as per textbook recommendations and compared to other studies $(4,5,10)$. This could be attributed to strict adherence to standard surgical techniques and safe anesthesia. The death rate is zero.

Finally, we can conclude that thyroid surgery constitutes a significant proportion of major elective general surgery. This study also showed that Colloid goiter (a preventable disease)was the commonest thyroid disease. Thyroid carcinoma pattern differs from the western world. Follicular carcinoma is common, which indicates also the high burden of multinodular goiter. In the Western world, papillary carcinoma is more common.

Public health measures such as iodination of salt and health education could play a role in reducing the occurrence of this disease especially in iodine deficient areas. It also helps to provide information about the treatment options so that patients could seek medical attention earlier.

\section{REFERENCES}

1. Abebe B, Girmaye T, Mensur O, Sentayehu T, Sissay B. The patterns of surgical thyroid diseases and operative treatment in Gondar College of Medical Sciences, north-west Ethiopia. East and Central African Journal of Surgery. 2004;9(1).

2. Mirzakarimov F, Odimba BF, Tembo P. Patterns of surgically treated thyroid disease in Lusaka, Zambia. Medical Journal of Zambia. 2012;39(4):7-11.

3. Mengistu M. The pattern of thyroid diseases in adult Ethiopians and experience in management. Ethiopian medical journal. 1993 Jan;31(1):25-36.

4. Tharwat I. Sulaiman, FRCSI, CABS, Salim A. Al-Sarraf * FRCS, Khudaya Al-Sarawak* DMRT; Changing Patterns of Thyroid
Pathology and Trends of Surgical Treatment, Fac Med Baghdad 2009; Vol. 51, No.1

5. Ogbera AO, Kuku SF. Epidemiology of thyroid diseases in Africa. Indian journal of endocrinology and metabolism. 2011 Jul;15(Suppl2):S82.

6. Bouq Y, Fazili FM, Gaffar HA. A current pattern of surgically treated thyroid diseases in the Medinah region of Saudi Arabia. $J K$ Practitioner. 2006 Jan;13(1):9-14.

7. Kolur A, Anitha B, Letha P, Joshi T, Ahmed $S$, Naik H. Pattern of thyroid disorder in thyroidectomy specimen. International Journal of Medical Science and Public Health. 2014 Dec 1;3(12):1446-9.

8. Tsegaye B, Ergete W. Histopathologic pattern of thyroid disease. East African medical journal. 2003;80(10):525-8.

9. Kharchenko VP, Kotlyarov PM, Mogutov MS, Alexandrov YK, Sencha AN, Patrunov YN, Belyaev DV. Ultrasound diagnostics of thyroid diseases. Springer Science \& Business Media; 2010 Sep 2.

10. Al-Amri AM. Pattern of thyroid cancer in the eastern province of Saudi Arabia: University hospital experience. Journal of cancer therapy. 2012 Jun 20;3(03):187.

11. Van Nostrand D. The benefits and risks of I131 therapy in patients with welldifferentiated thyroid cancer. Thyroid. 2009 Dec 1;19(12):1381-91.

12. Mezgebu Y, Mossie A, Rajesh PN, Beyene G. Prevalence and serverity of Iodine deficiency disorder among children 6-12 years of age in ShebeSenbo District, Jimma Zone, Southwest Ethiopia. Ethiopian journders, For the Ethiopian Health Center Team, Ethiopia public health training intiative, page 11, 2007al of health sciences. 2012;22(3).

13. Anwar Yibrie, Sisay Yifru, Desalegn, Tigabu, Yifokir Tefera, TakeleTekelu, Taddis Birhane, Iodine Deficiency Disorder 